\title{
Numerical Investigation on Vibrational Characteristics of Glass Reinforced Polyester Composite Plate
}

\author{
Dr. S. Periyasamy ${ }^{1}$, Mr. I. Mohamed Akbarali ${ }^{2}$, Mr. Premkumar B ${ }^{3}$. \\ ${ }^{1}$ Assistant Professor, \\ ${ }^{2,3} \mathrm{PG}$ Scholar \\ Department of Mechanical Engineering, \\ Government College of Technology, Coimbatore, \\ Tamil Nadu, India
}

\begin{abstract}
Composite materials are increasingly used in aerospace, naval and high performance civil engineering structures due to specific strength, stiffness, corrosion resistance large fatigue life and stealth characteristics. The reinforcement of Composites with industry driven woven fiber materials lead to improved properties of composite structures in terms of acoustical, elastic and thermal properties. Glass fibers are the most commonly used ones in low to medium performance composites because of their high tensile strength and low cost. In woven fiber composites, fibers are woven in both principal directions at right angles to each other (warp and fill Directions). To better understand any structural vibration problem, the resonant frequencies of a structure need to be identified and quantified. Today, due to the advancement in computeraided data acquisition systems and Instrumentation, experimental modal analysis has become an extremely important tool in the hands of an experimentalist. So, the modal analysis of laminated composite plates is of tremendous importance to predict the dynamic behaviour of structures.
\end{abstract}

Keywords: Composite, Glass fiber, Modal analysis, vibration.

\section{INTRODUCTION}

Glass fibers were prepared using melt spinning technique. These involve melting the glass composition into platinum crown which has small holes for flow of molten glass. Continuous fibers can be drawn out through the holes and wound into spindles, while the woven fibers were produced by close arrangements of long fibers similar to the arrangement of tread in clothes. Based on their arrangement they may be classified as unidirectional and bidirectional fibers. Fiber dimensions and to some extent properties can be controlled process variables such as melts temperature and spinning rate. Glass fibre reinforced with resin always possess varying properties with the variation in the direction of plyorientation of ply and number of ply. The different types of glass fibers used based on their mixture of various materials are as follows: A GLASS - Soda lime silicate glasses were used for higher strength durability, and good electrical resistivity as compared to other glass fiber types.

C GLASS - In the high corrosive environments, Calcium borosilicate glasses used because of its higher chemical stability.
D GLASS- Borosilicate glasses with a low dielectric constant were mainly finds the applications in electrical fields.

E GLASS - Alumina-calcium-borosilicate glasses possess maximum alkali content used as general purpose fibers where strength and high electrical resistivity are required. ECR GLASS - Calcium alumino silicate glasses with a maximum alkali content used where strength, electrical resistivity, and acid corrosion resistance are required.

The main objective of this research work is to study and compare numerical result (deflection and natural frequency) on the glass reinforced polyester composite plates.

The different ply and different support is given to the composite model for analysis the vibration behaviour of the plate. The best construction of the glass fiber reinforced with polyester resin composite plate was found by comparing the results of the composite plate .different length and berth ratio is taken for another parameter in this project. The prediction of dynamic behavior of laminated composite plates plays a significant role in the future applications of structural composites. The check influence of glass fiber percentage on the mechanical properties such as tensile strength and Poisson ratio were investigated. These composite plates possess high strength to weight ratio which can be used in winds of high-speed aircraft rockets $s$ and other related space vehicles.

\section{PROBLEM WITH COMPOSITE MATERIAL}

There are several inherent difficulties in detecting damage in composite materials as opposed to traditional engineering such as plastics. One reason is due to its nonhomogeneity ty and anisotropy; most metals and plastics are formed by one Type of uniformly isotropic material with very well-known properties. On the other hand, composite material can have a widely varying set of material properties based on the chosen fibers, matrix and manufacturing process. This makes model composite complex and often a mix between materials with widely differing properties. The most difficult is the damage in composite material often occurs below the surface, which further prevents the implementation of several detection methods. The importance of damage detection for composite structures is often emphasized over that of metallic or plastic structures because of their load bearing requirements. 
The analysis of vibration monitoring data to monitor the characterisic changes in rotating machinery caused by imbalance, misalignment, bent shaft, mechanical looseness, faults in gear drives, defects in rolling-element bearings and defects in sleeve bearings. Vibration Analysis used to detect early precursors to machine failure, allowing machinery to repaired or replaced before an expensive failure occurs.

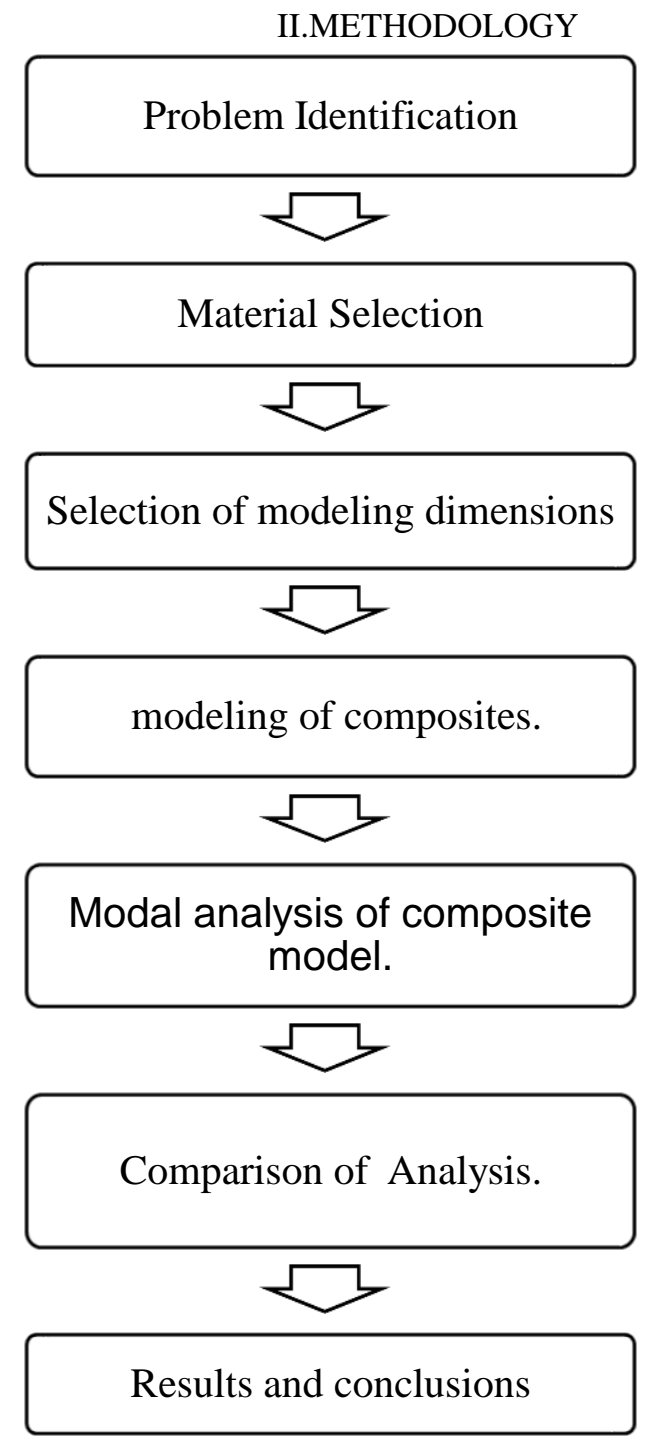

Fig 1: Methodology flow chart

III.MATERIAL SELECTION

\section{MECHANICAL PROPERTIES POISSON RATIO}

The characteristics of fiber Glass composite plate which can be determined completely by four material constants: $\mathrm{E}_{1}, \mathrm{E}_{2} \mathrm{G}_{12}$, and $\mathrm{u}_{12}$ where the suffixes 1 and 2 indicate principal material directions. For material characterization of composites, laminate having different layers was manufactured to evaluate the material constants.

. The dimension of the specimen was taken as specified in ASTM D638 is represented in table 3.1 below:
Table 1: Size of the specimen for tensile test.

\begin{tabular}{|c|c|c|}
\hline $\begin{array}{c}\text { LENGTH } \\
(\mathbf{m m})\end{array}$ & $\begin{array}{c}\text { WIDTH } \\
(\mathbf{m m})\end{array}$ & $\begin{array}{c}\text { THICKNESS } \\
(\mathbf{m m})\end{array}$ \\
\hline 165 & 13 & 4 \\
\hline
\end{tabular}

\section{PROPERTIES OF GLASS REINFORCED}

POLYESTER:

The mechanical properties of polyester composite plate are given below,

- Length of the composite $=150 \mathrm{~mm}$

- Breadth of the composite $=75 \mathrm{~mm}$

- Young's modulus $=2 \mathrm{x} \mathrm{E}^{11} \mathrm{pa}$

- $\quad$ Poisson ratio $=0.3$

- $\quad$ Bulk modulus= $1.6667 \mathrm{E}^{11} \mathrm{pa}$

IV.MODELLING OF COMPOSITE PLATE

The below figure shows the composite plate with different aspect ratios.

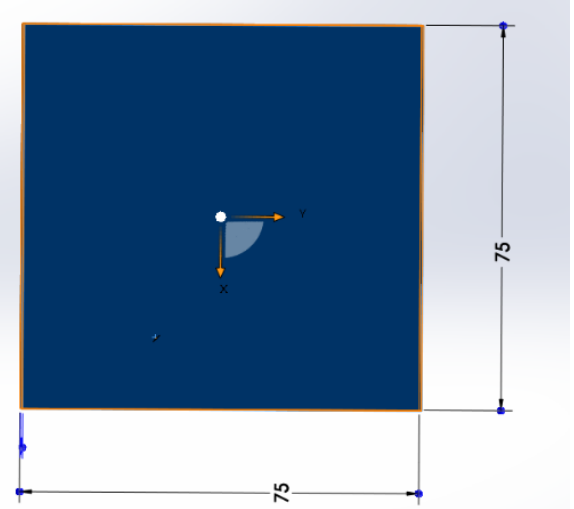

Fig 2: Model of composite plate with 1:1 aspect ratio

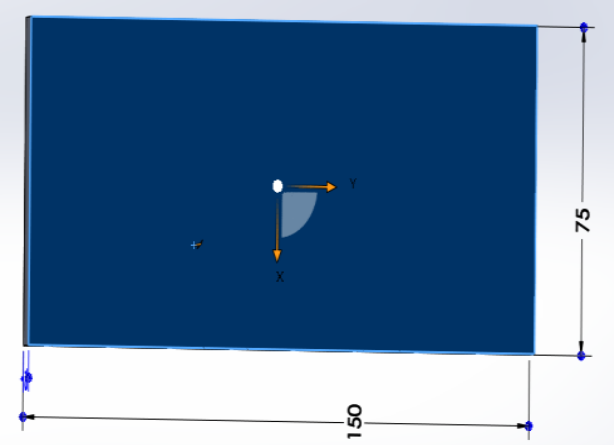

Fig 3: Model of composite plate with 1:1 aspect ratio

V.RESULTS AND DISCUSSION

\section{MODAL ANALYSIS}

Natural frequencies of the composite plate of 5 ply composite plate with aspect ratio of $1: 1$ and 2:1 are calculated using Numerical Analysis -ANSYS. 


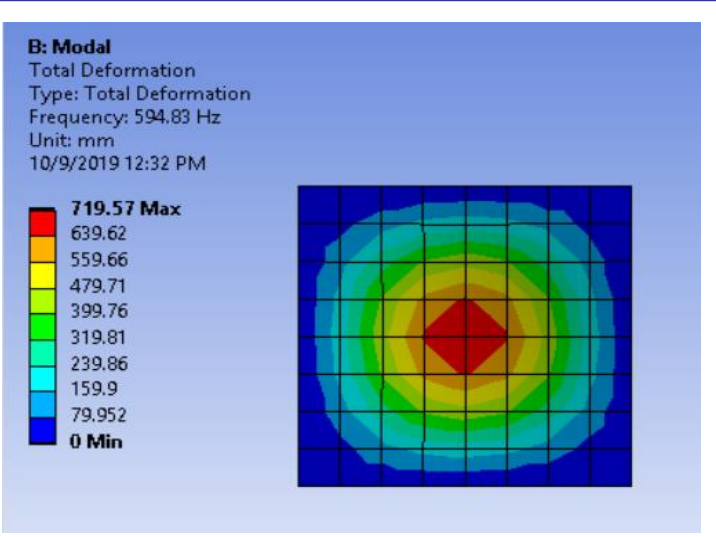

Fig 4: Modal shape of first deformation for aspect ratio 1:1.

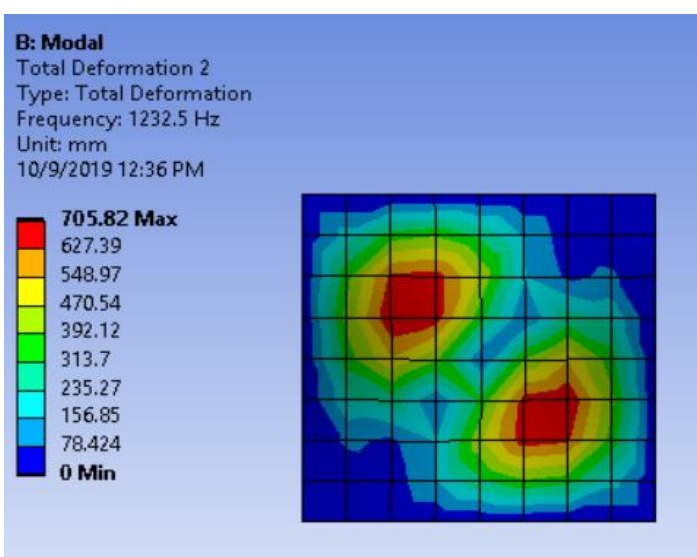

Fig 5: Modal shape of second deformation for aspect ratio 1:1.

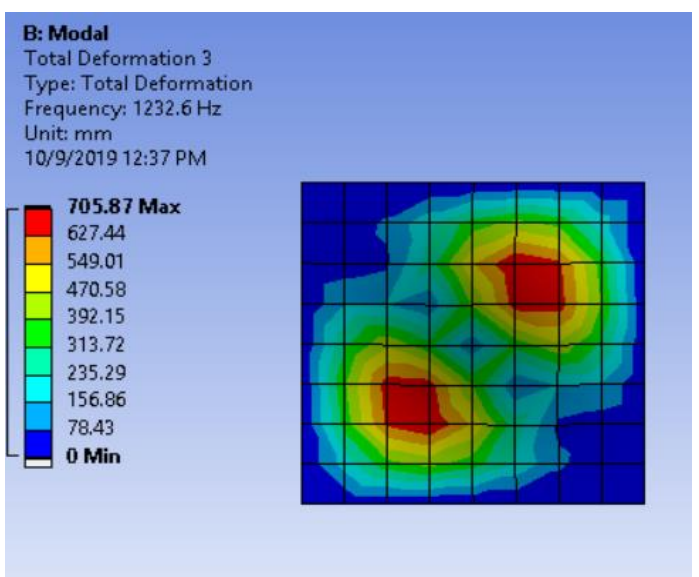

Fig 6: Modal shape of third deformation for aspect ratio 1:1.

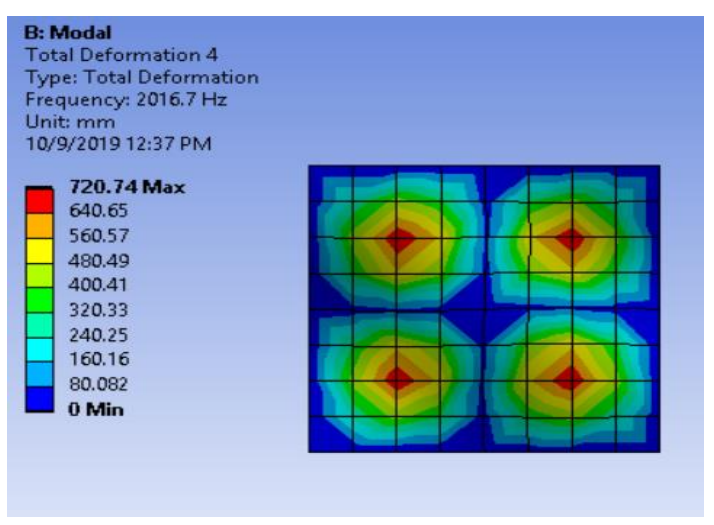

Fig 7: Modal shape of fourth deformation for aspect ratio 1:1.

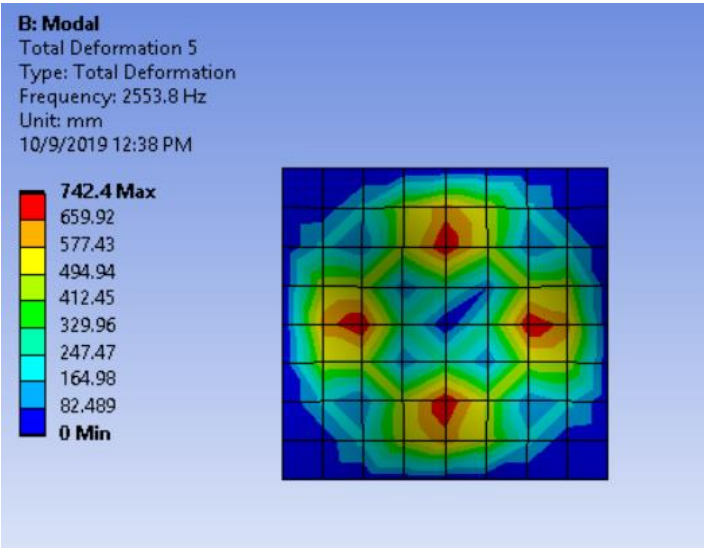

Fig 8: Modal shape of fivth deformation for aspect ratio 1:1.

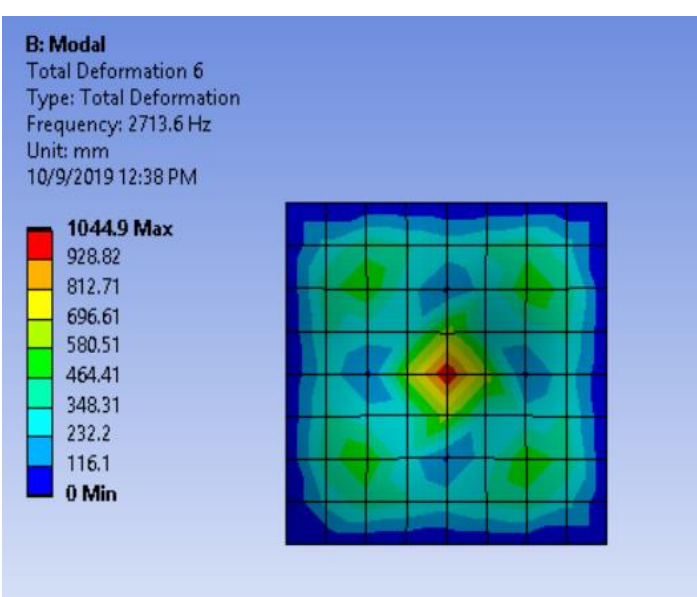

Fig 9: Modal shape of sixth deformation for aspect ratio 1:1.

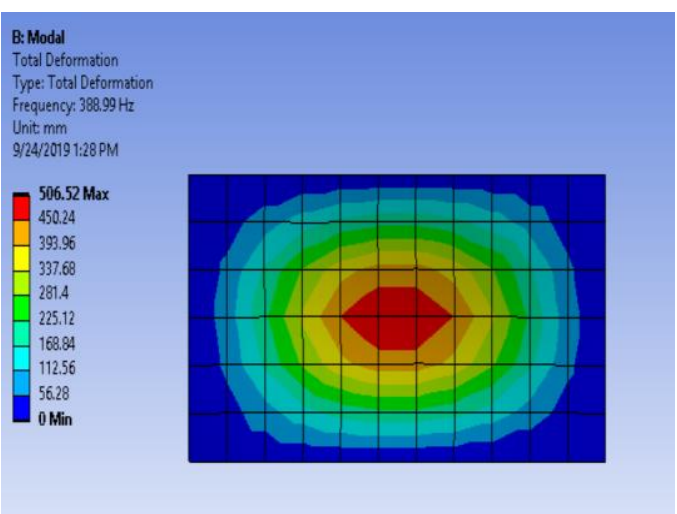

Fig 10: Modal shape of third deformation for aspect ratio $2: 1$.

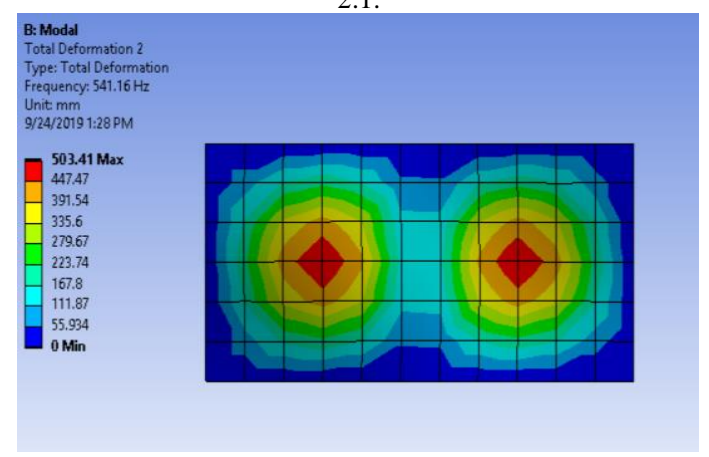

Fig 11: Modal shape of third deformation for aspect ratio $2: 1$. 


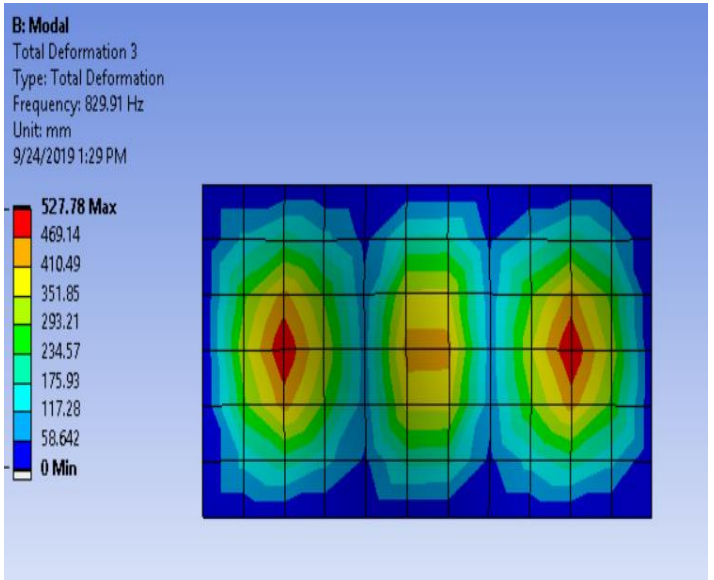

Fig 12: Modal shape of third deformation for aspect ratio 2:1.

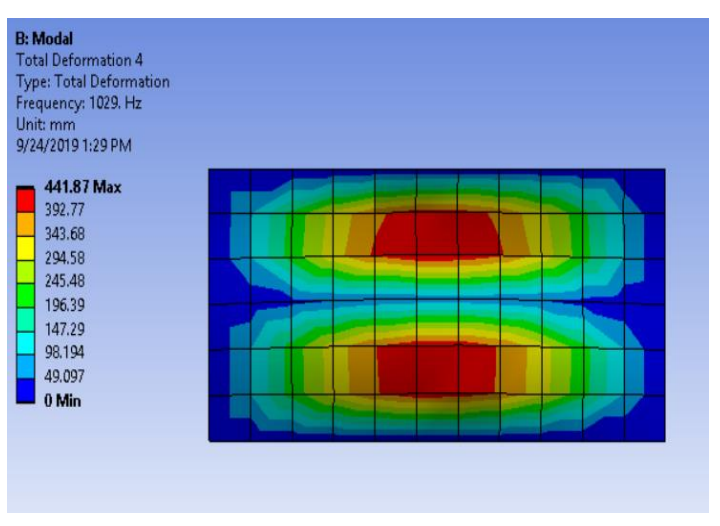

Fig 13: Modal shape of third deformation for aspect ratio 2:1.

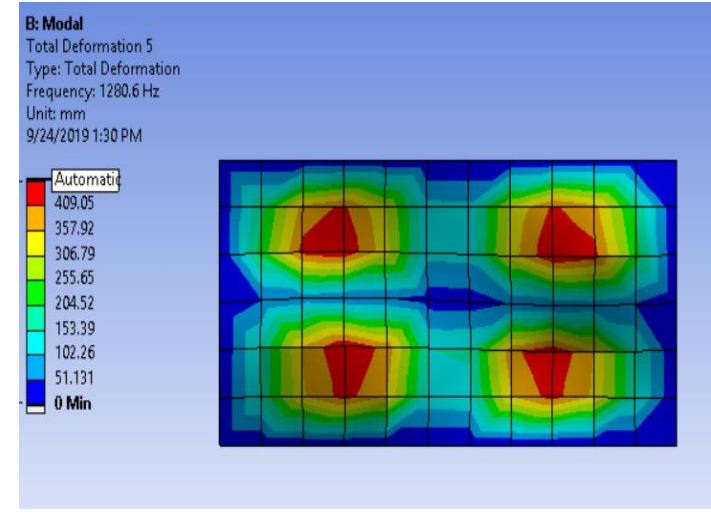

Fig 14: Modal shape of third deformation for aspect ratio 2:1.

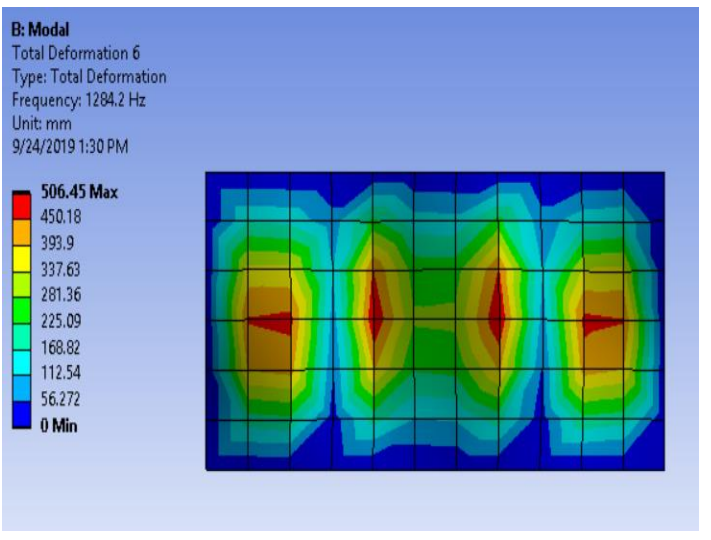

Fig 15: Modal shape of third deformation for aspect ratio 2:1.

Table 2: Natural frequencies in Hertz of 5 ply composite plate

\begin{tabular}{|c|c|c|c|c|c|c|}
\hline \multirow[t]{3}{*}{ Mode no } & \multicolumn{6}{|c|}{5 plies } \\
\hline & \multicolumn{3}{|c|}{ Length berth ratio $=1: 1$} & \multicolumn{3}{|c|}{ Length berth ratio $=2: 1$} \\
\hline & SSSS & CFFF & $\mathrm{CCCF}$ & SSSS & CFFF & $\mathrm{CCCF}$ \\
\hline 1 & 594.83 & 566.63 & 508.05 & 388.99 & 160.44 & 247.7 \\
\hline 2 & 1232.5 & 70.92 & 840.91 & 541.16 & 378.24 & 17.542 \\
\hline 3 & 1232.6 & 172.83 & 1461.2 & 529.91 & 557.24 & 74.956 \\
\hline 4 & 2016.7 & 447.31 & 1699.9 & 1029 & 743.75 & 111.31 \\
\hline 5 & 2553.8 & 645.91 & 1802.9 & 1280.6 & 776.02 & 247.7 \\
\hline 6 & 2713.6 & 1135.6 & 2611.3 & 1284.2 & 1141.6 & 324.11 \\
\hline
\end{tabular}

Table 3 Deformation in mm of 5 ply composite plate

\begin{tabular}{|c|c|c|c|c|c|c|}
\hline \multirow{3}{*}{ Mode no } & \multicolumn{6}{|c|}{5 plies } \\
\hline & \multicolumn{3}{|c|}{ Length berth ratio $=1: 1$} & \multicolumn{3}{|c|}{ Length berth ratio $=2: 1$} \\
\hline & SSSS & CFFF & $\mathrm{CCCF}$ & SSSS & CFFF & $\mathrm{CCCF}$ \\
\hline 1 & 719 & 1151 & 958 & 506 & 677 & 690 \\
\hline 2 & 705 & 635 & 1016 & 503 & 649 & 447 \\
\hline 3 & 705 & 926 & 888 & 527 & 688 & 598 \\
\hline 4 & 720 & 804 & 1036 & 441 & 634 & 460 \\
\hline 5 & 742 & 989 & 937 & 400 & 714 & 690 \\
\hline 6 & 1044 & 1010 & 1043 & 506 & 712 & 519 \\
\hline
\end{tabular}




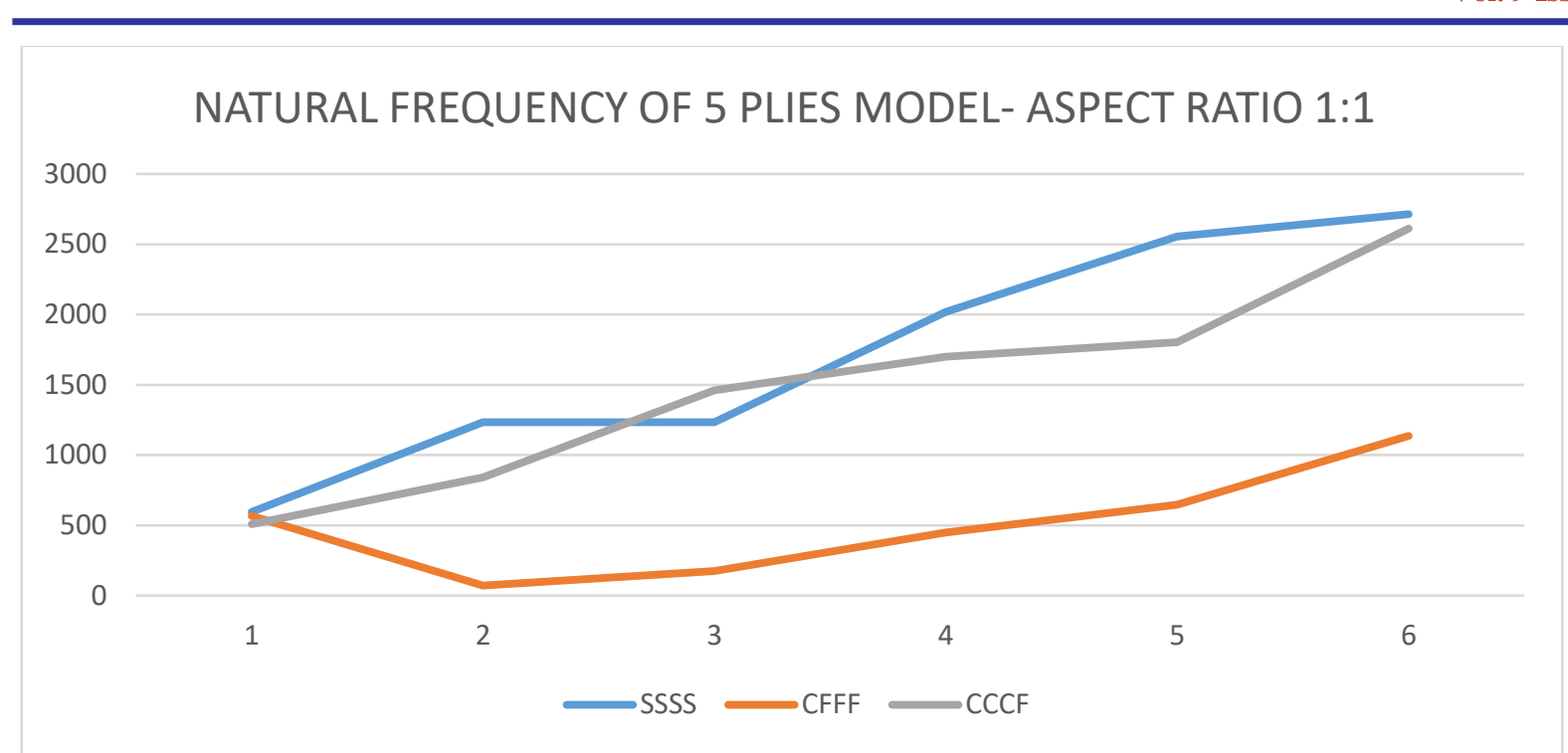

Fig 16: NATURAL FREQUENCY OF 5 PLIES MODEL- ASPECT RATIO 1:1

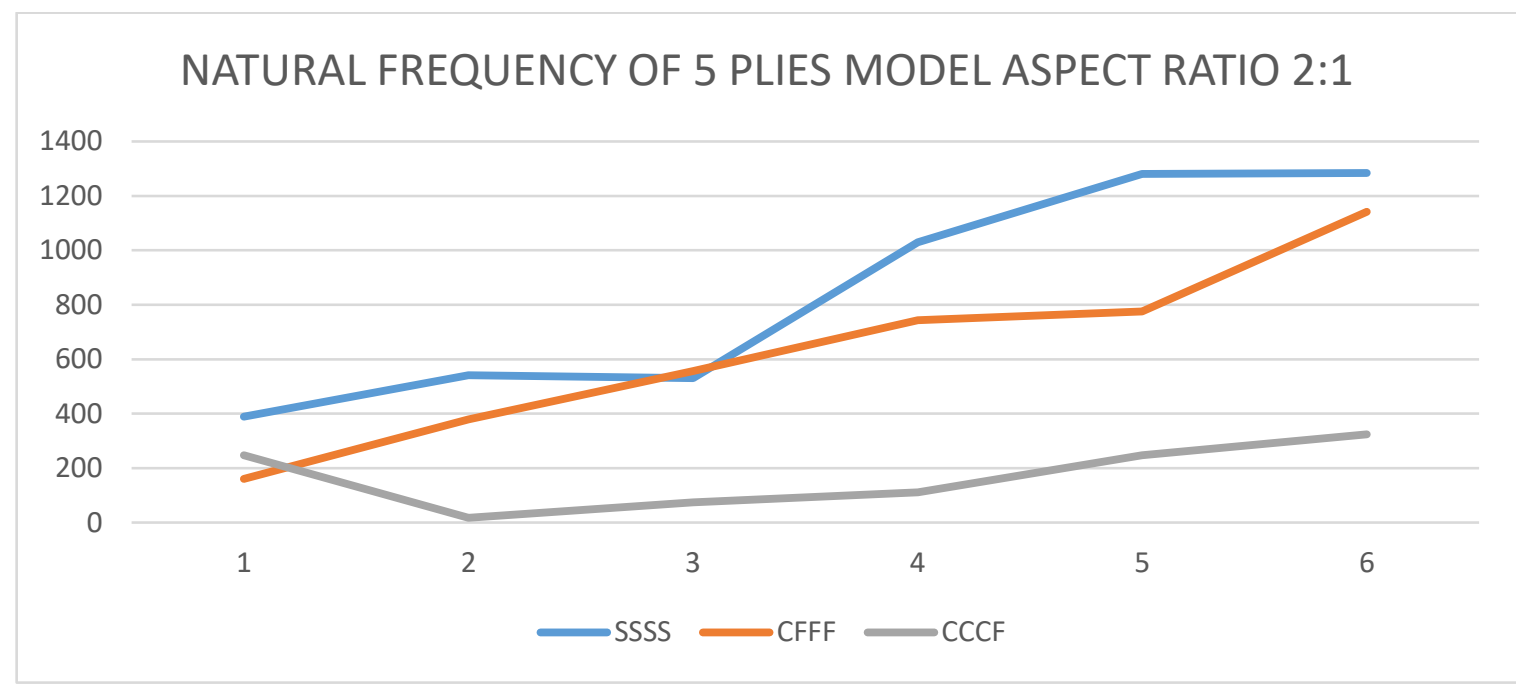

Fig 17: NATURAL FREQUENCY OF 5 PLIES MODEL -ASPECT RATIO 2:1

From table 5.2, for $1 / \mathrm{b}$ ratio $1: 1$ and $2: 1$ minimum frequency occurs at all side simply supported and for $1 / \mathrm{b}$ ratio $1: 1$ maximum frequency occurs in three side cantilever and one side fixed and for $1 / \mathrm{b}$ ratio 2:1 maximum frequency occurs in one side cantilever support and three side fixed support.

Table 4: Natural frequencies in Hertz of 10 ply composite plate

\begin{tabular}{|c|c|c|c|c|c|c|}
\hline \multirow[t]{3}{*}{ Mode no } & \multicolumn{6}{|c|}{10 plies } \\
\hline & \multicolumn{3}{|c|}{ Length berth ratio $=1: 1$} & \multicolumn{3}{|c|}{ Length berth ratio $=2: 1$} \\
\hline & SSSS & CFFF & $\mathrm{CCCF}$ & SSSS & CFFF & $\mathrm{CCCF}$ \\
\hline 1 & 81.751 & 2220.9 & 6667.4 & 81.749 & 6179.6 & 734.32 \\
\hline 2 & 81.751 & 2969.6 & 8076 & 81.751 & 6883.8 & 1482.4 \\
\hline 3 & 81.752 & 5319.3 & 10822 & 81.751 & 7489 & 2653 \\
\hline 4 & 8249.3 & 5518.3 & 11245 & 3479 & 9660.3 & 2727.9 \\
\hline 5 & 8441.7 & 6007.2 & 12327 & $5221 . .2$ & 10248 & 2821.1 \\
\hline 6 & 8831.4 & 6667.9 & 12527 & 5858.3 & 11038 & 2824.5 \\
\hline
\end{tabular}

Table 5: Deformation in mm of 10 ply composite plate

\begin{tabular}{|c|c|c|c|c|c|c|}
\hline \multirow[t]{3}{*}{ Mode no } & \multicolumn{6}{|c|}{10 plies } \\
\hline & \multicolumn{3}{|c|}{ Length berth ratio $=1: 1$} & \multicolumn{3}{|c|}{ Length berth ratio $=2: 1$} \\
\hline & SSSS & CFFF & $\mathrm{CCCF}$ & SSSS & CFFF & $\mathrm{CCCF}$ \\
\hline 1 & $2 * \mathrm{E}^{-4}$ & 0.16 & 14.28 & $8.94 * \mathrm{E}^{-4}$ & 10.18 & 0.14 \\
\hline 2 & $2.06 * \mathrm{E}^{-4}$ & 9.97 & 0.16 & $1.61 * \mathrm{E}^{-4}$ & 0.28 & 7.05 \\
\hline 3 & $1.12 * \mathrm{E}^{-4}$ & 0.14 & 14.65 & $1.04 * \mathrm{E}^{-4}$ & 10.31 & 0.20 \\
\hline 4 & $2.7 * E^{-3}$ & 20.25 & 0.21 & $5.57 * \mathrm{E}^{-3}$ & 10.60 & 14.31 \\
\hline 5 & 14.42 & 0.47 & 0.38 & $7.39 * \mathrm{E}^{-2}$ & 0.32 & 13.47 \\
\hline 6 & $2.4 * E^{-2}$ & 14.27 & 14.83 & $5.06 * \mathrm{E}^{-3}$ & 0.14 & 15.18 \\
\hline
\end{tabular}




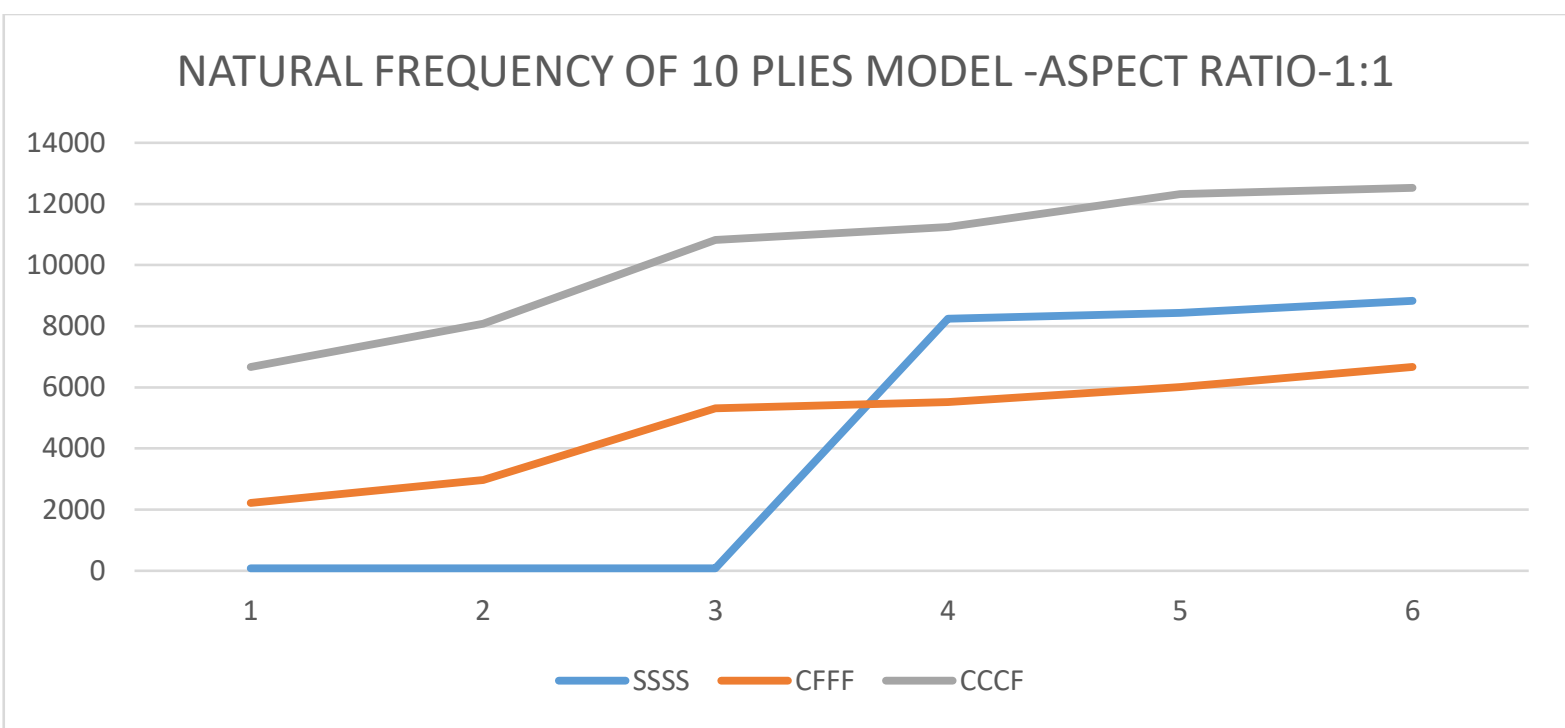

Fig 18: NATURAL FREQUENCY OF 10 PLIES MODEL -ASPECT RATIO1:1

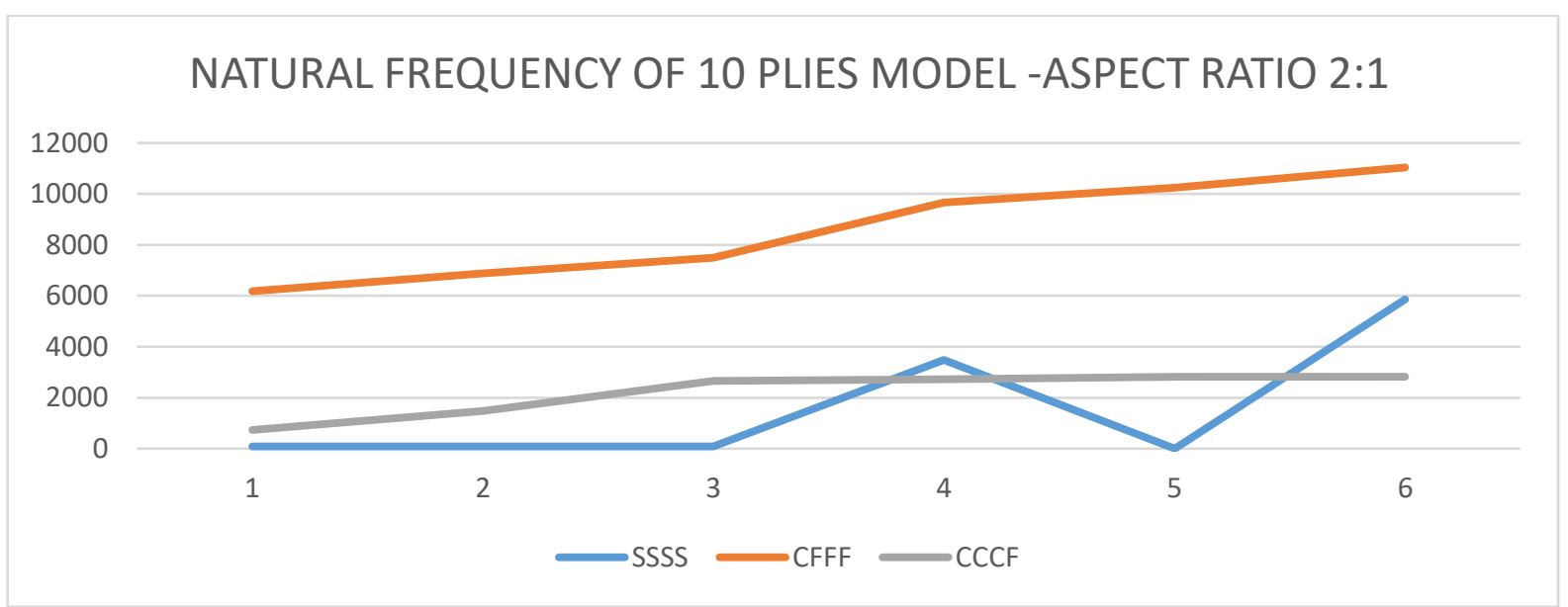

Fig 19: NATURAL FREQUENCY OF 10 PLIES MODEL -ASPECT RATIO 2:1

From table 5.3, for $1 / \mathrm{b}$ ratio $1: 1$ and 2:1 minimum frequency occurs at all side simply supported and for $1 / \mathrm{b}$ ratio $1: 1$ maximum frequency occurs in three side cantilever and one side fixed and for $1 / b$ ratio $2: 1$ maximum frequency occurs in one side cantilever support and three side fixed support.

Table 6 Natural frequencies in Hertz of 15 ply composite plate

\begin{tabular}{|l|l|l|l|l|l|l|}
\hline \multirow{2}{*}{ Mode no } & \multicolumn{5}{|c|}{15 plies } \\
\cline { 2 - 7 } & \multicolumn{4}{|c|}{ Length berth ratio = 1:1 } & \multicolumn{4}{c|}{ Length berth ratio = 2:1 } \\
\hline & SSSS & CFFF & CCCF & SSSS & CFFF & CCCF \\
\hline 1 & 54.501 & 2220.6 & 6667.5 & 54.5 & 6179.7 & 2756.1 \\
\hline 2 & 54.501 & 2970 & 8075.9 & 54.501 & 6883.8 & 2973.7 \\
\hline 3 & 54.501 & 5319.2 & 10821 & 54.501 & 7488.8 & 4206.9 \\
\hline 4 & 8249.1 & 5534 & 11245 & 3478.5 & 9660.6 & 5109.7 \\
\hline 5 & 8441.9 & 6007.3 & 12327 & 5220.9 & 10248 & 5555.8 \\
\hline 6 & 8831.2 & 6667.8 & 12527 & 5858 & 11038 & 5687.5 \\
\hline
\end{tabular}

Table 7: Deformation in mm of 15 ply composite plate

\begin{tabular}{|c|c|c|c|c|c|c|}
\hline \multirow[t]{3}{*}{ Mode no } & \multicolumn{6}{|c|}{15 plies } \\
\hline & \multicolumn{3}{|c|}{ Length berth ratio $=1: 1$} & \multicolumn{3}{|c|}{ Length berth ratio $=2: 1$} \\
\hline & SSSS & CFFF & $\mathrm{CCCF}$ & SSSS & CFFF & $\mathrm{CCCF}$ \\
\hline 1 & $3.47 * \mathrm{E}^{-5}$ & $8.96 * \mathrm{E}^{-2}$ & 11.66 & $2.29 * \mathrm{E}^{-4}$ & 8.316 & 0.11 \\
\hline 2 & $3.475 * \mathrm{E}^{-5}$ & 8.14 & 0.09 & $1.93 * \mathrm{E}^{-5}$ & 0.15 & 5.77 \\
\hline 3 & $2.14 * \mathrm{E}^{-6}$ & $7.61 * \mathrm{E}^{-2}$ & 11.96 & $2.67 * \mathrm{E}^{-5}$ & 8.42 & 8.21 \\
\hline 4 & $1.48 * \mathrm{E}^{-3}$ & 16.45 & 0.11 & $3.03 * \mathrm{E}^{-3}$ & 8.65 & $9.91 * \mathrm{E}^{-2}$ \\
\hline 5 & 11.77 & 0.26 & 0.20 & 0.04 & 0.17 & 11.69 \\
\hline 6 & $1.32 * \mathrm{E}^{-2}$ & 11.65 & 12.11 & $2.73 * \mathrm{E}^{-3}$ & 0.07 & $9.68 * \mathrm{E}^{-2}$ \\
\hline
\end{tabular}




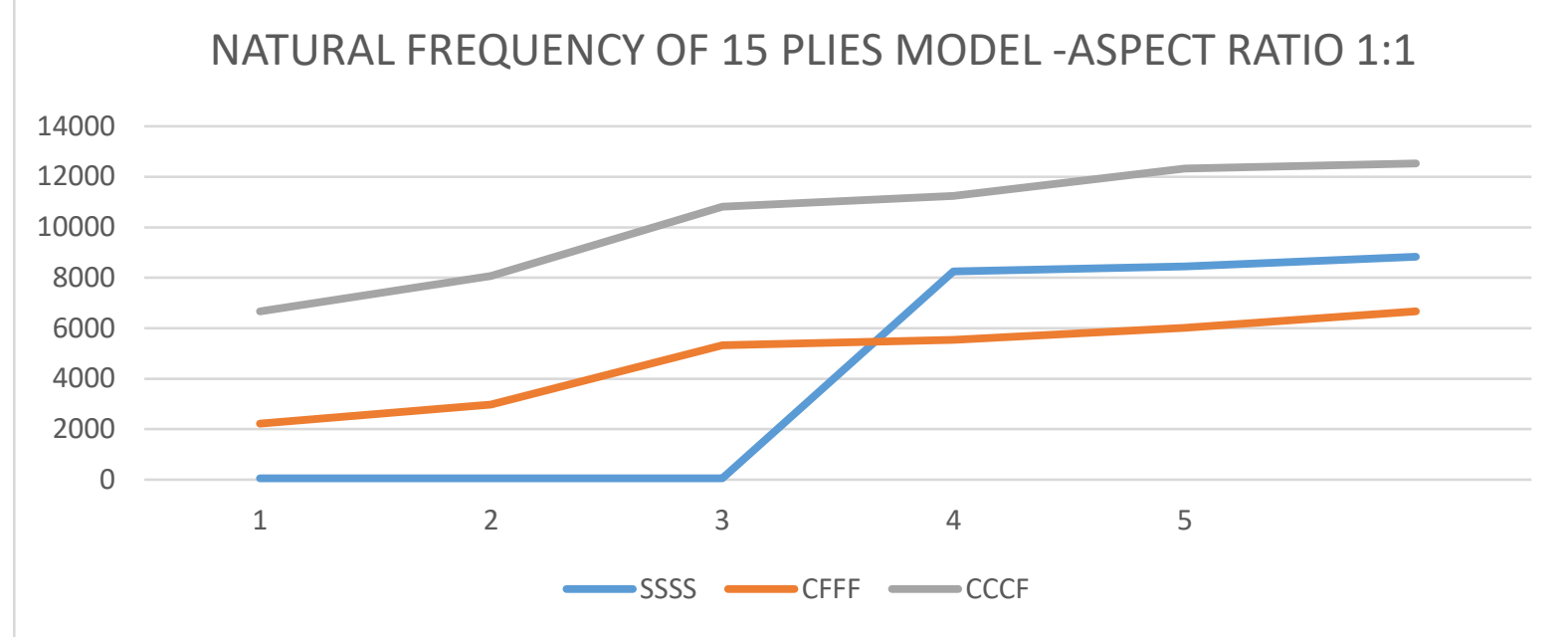

Fig 20: NATURAL FREQUENCY OF 15 PLIES MODEL -ASPECT RATIO 1:1

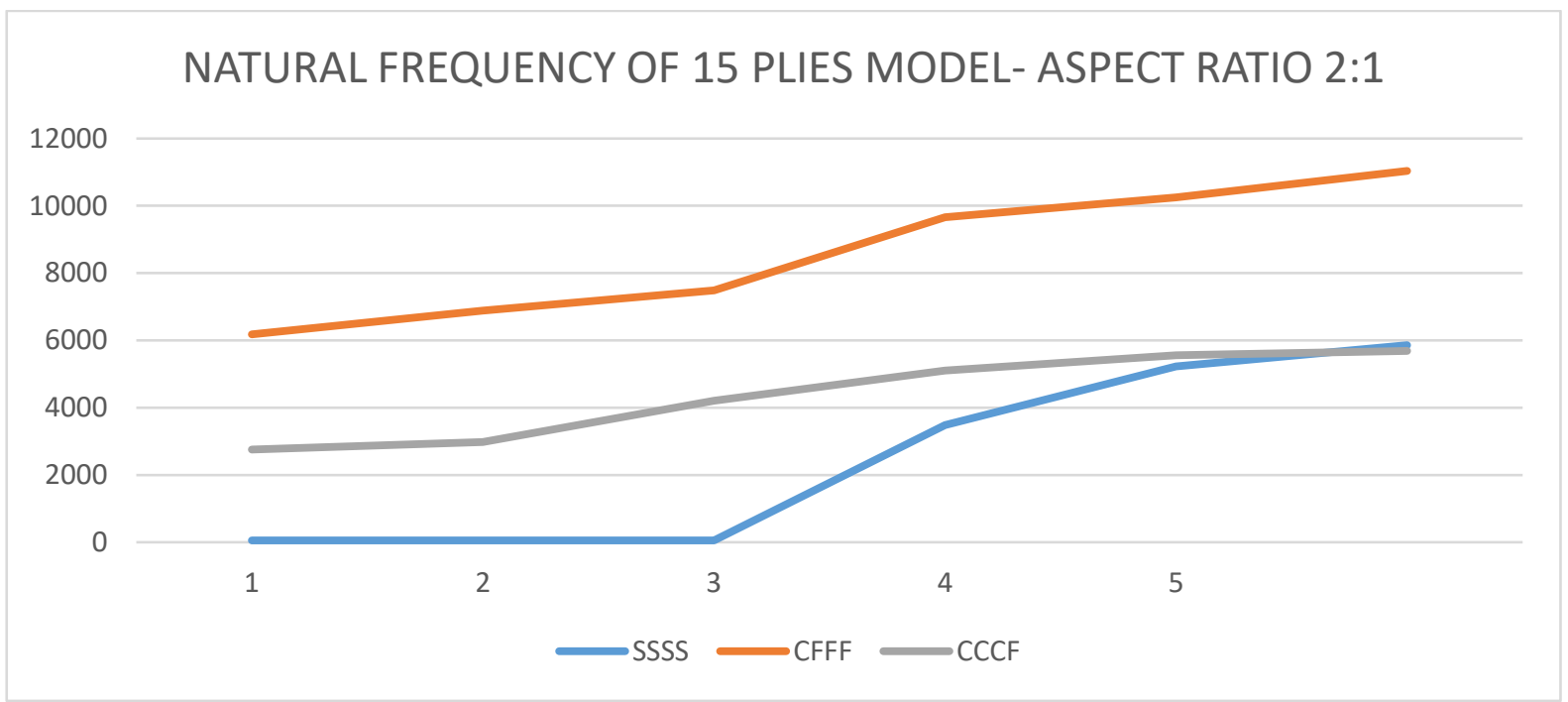

Fig 21: NATURAL FREQUENCY OF 15 PLIES MODEL- ASPECT RATIO 2:1

Glass reinforced polyester composite plate with varying number of plies and different length to width ratio were numerically analyzed and compared. The effect of different parameter like number of layers, aspect ratio and boundary conditions including cantilever, simply supported and fully clamped was investigated. For simply supported boundary there is decrease in natural frequency as well as deformation with increase in number of plies. Thus, the dynamic behavior of the composite plate is greatly influenced by the number of the composite layers. There is 5 to $10 \%$ of reduction in natural frequencies in between 5 plies and 10 plies model. This natural frequency is used to determine the frequency at which resonance occurs.

\section{VI.REFERENCE}

[1] Begum K. and Islam M.A., "Natural Fiber as a substitute to Synthetic Fiber in Polymer Composites: " Research Journal of Engineering Sciences, vol. 2, pp. 46-53, 2013.

[2] S.V. Joshi, L.T. Drzal, A.K. Mohanty and S. Arora, "Are natural fiber composites environmentally superior to glass fiber," Composites Part: A, vol. 35, pp. 371-376, 2004.

[3] Eberle R and Franze H., "Modeling the use phase of passenger cars in LCI," in SAE Total Life-cycle Conference, Graz Austria, 1998.

[4] R. Bhoopathi, M. Ramesh and C. Deepa, "Fabrication and Property Evaluation of Banana-Hemp-Glass Fiber Reinforced Composites," in 12th Global Congress on Manufacturing and Management, 2014.

[5] M. Ramesh, K. Palanikumar and K. Hemachandra Reddy, "reinforced, Mechanical property evaluation of sisal-jute-glass fiber," Composite: Part B, vol. 48, pp. 1-9, 2013.

[6] Ebrahim Sadeghpour, Mojtaba Sadighi, Abdolreza Ohadi, 2016 "Free Vibration Analysis of a Debonded Curved Sandwich Beam", European Journal of Mechanics - A/Solids, 57, pp. 71-84

[7] Shi Cheng, Pizhong Qiao, Fangliang Chen, Wei Fan, Zhende Zhu, 2015 "Journal of Sandwich Structures and Materials", 18, 2, pp 119.

[8] Yong-Bae Cho \& Ronald C. Averill, 1997 "An improved theory and finite-element model for laminated composite and sandwich beams using first-order zig-zag sub laminate approximations", Composite Structure, 37, pp. 281-298.

[9] S. Seren Akavci, Huseyin R. Yerli and Ali Dogan, 2007 "The first order shear deformation theory for symmetrically laminated composite plates on elastic foundation", The Arabian Journal for Science and Engineering, 32, pp 2B.

[10] I. Ergatoudis, B. M. Irons and C. Zienkiewicz, 1968 "Curved, isoparametric, quadrilateral elements for finite element analysis", Solids Structures, 4, pp 31-42.

[11] Dipak Kr. Maiti \& P. K. Sinha. Bending and free vibration analysis of shear deformable laminated composite beams by finite element method. Composite Structures, 29 (1994): 421- 431.

[12] R.A. Jafari-Talookolaei and M.T.Ahmadian.Free Vibration Analysis of a Cross-Ply Laminated Composite Beam on Pasternak Foundation. Journal of Computer Science, 3 (2007): 51-56. 
[13] Kapania RK, Raciti S. Recent advances in analysis of laminated beams and plates: Part I. Shear effects and buckling; Part II. Vibrations and wave propagation. AIAA Journal, 27 (1989): 92346.

[14] Teboub Y, Hajela P. Free vibration of generally layered composite beams using symbolic computations. Composite Structures, 33 (1995): 123-34

[15] Bassiouni AS, Gad-Elrab RM, Elmahdy TH. Dynamic analysis for laminated composite beams. Composite Structures, 44 (1999): 817.

[16] Banerjee, J.R. Free vibration of axially loaded composite Timoshenko beams using the dynamic stiffness matrix method. Computers \& Structures, 69 (1998): 197-208.
[17] Yuan, F.G. and R.E. Miller. A higher order finite element for laminated composite beams. Computers \& Structures, 14 (1990): 125-150. References National Institute of Technology, Rourkela Page 45

[18] Krishnaswamy, S., K. Chandrashekhara and W.Z.B. Wu Analytical solutions to vibration of generally layered composite beams. J. Sound and Vibration, 159 (1992): 85-99.

[19] Chandrashekhara, K., K. Krishnamurthy and S. Roy. Free vibration of composite beams including rotary inertia and shear deformation. Composite Structures, 14 (1990): 269-279.

[20] Reddy JN. Introduction to the finite element method 2nd ed. New York: McGraw Hill, 1993.

[21] S. S. Rao, The Finite Element Method In Engineering, 2011. 